\title{
Performance Expectations for IT Graduates in Software Development
}

By Dr. Anuradha Jayakody, A.S.K. Bulathsinghala, L.G.C.S. Lihinigama, K.H.A. Anurad \& D.M.K.N. Karunarathna Sri Lanka Institute of Information Technology,

Abstract- Technology makes the world more connected than it did yesterday, and it integrates worldwide activities in a blink of an eye. In the IT sector, there are several job roles as identified under software development. These job roles have different duties and tasks which requires employees, with a unique set of skills to match the specific requirements in the field. During the past few decades, the employment landscape has changed, and new occupations are rising in the field of software development, yet no satisfactory evidence has been provided by existing literature on the performance expectations in the industry, for IT graduates in software development, in the Sri Lankan context. Therefore, this research objectives to ascertain the expectations of employers on the technical, personal, educational, and general competencies of employees, holding an IT degree and to draw differences among individual and teamwork settings according to the identified competencies.

Keywords: competencies, IT graduates, IT professionals, software development industry, work expectations.

GJCST-H Classification: K.6.3

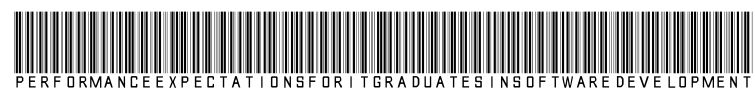

Strictly as per the compliance and regulations of:

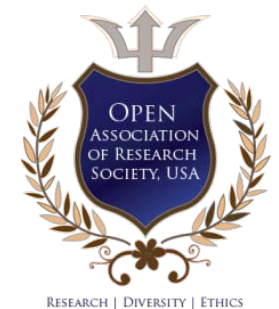

(c) 2019. Dr. Anuradha Jayakody, A.S.K. Bulathsinghala, L.G.C.S. Lihinigama, K.H.A. Anurad \& D.M.K.N. Karunarathna. This is a research/review paper, distributed under the terms of the Creative Commons Attribution-Noncommercial 3.0 Unported License http://creativecommons.org/licenses/by-nc/3.0/), permitting all non commercial use, distribution, and reproduction in any medium, provided the original work is properly cited. 


\title{
Performance Expectations for IT Graduates in Software Development
}

\author{
Dr. Anuradha Jayakody ${ }^{\alpha}$, A.S.K. Bulathsinghala ${ }^{\sigma}$, L.G.C.S. Lihinigama $^{\rho}$, K.H.A. Anurad $^{\omega}$ \\ \& D.M.K.N. Karunarathna
}

Abstract-Technology makes the world more connected than it did yesterday, and it integrates worldwide activities in a blink of an eye. In the IT sector, there are several job roles as identified under software development. These job roles have different duties and tasks which requires employees, with a unique set of skills to match the specific requirements in the field. During the past few decades, the employment landscape has changed, and new occupations are rising in the field of software development, yet no satisfactory evidence has been provided by existing literature on the performance expectations in the industry, for IT graduates in software development, in the Sri Lankan context. Therefore, this research objectives to ascertain the expectations of employers on the technical, personal, educational, and general competencies of employees, holding an IT degree and to draw differences among individual and teamwork settings according to the identified competencies. A survey method was used to gather data from IT professionals engaged in the software development industry of Sri Lanka, and the analyzed using correlation test. Accordingly, this research will fulfill its objectives and purpose of providing IT employers with a proper guide, explaining which competencies they should look for in the recruitment of IT graduates.

Keywords: competencies, IT graduates, IT professionals, software development industry, work expectations.

\section{INTRODUCTION}

T he software development industry is rapidly increasing along with new technological improvement day by day. Apart from the industry, when it comes to software development, there is a specific process, experts in the software development industry have to practice (Lunn, 2003).In regards to the implementation of software, it is necessary to understand the phases precisely by employees to perform well. That is the reason for employers being a concern to choose recruits for their company.

In the software development industry, there are job roles which are equally critical. With the increase of the technology, every organization using IT which can grab the full advantage. By using information technology, companies eventually end up with

Author a: Senior Lecturer, Faculty of Computing, Sri Lanka Institute of Information Technology, Malabe. e-mail: anuradha.j@sliit.lk

Author $\sigma \rho \omega ¥$ : Faculty of Business, Sri Lanka Institute of Information Technology, Malabe. e-mails: askbulathsinghala@gmail.com, chandulalihinigama777@gmail.com, asitha.anurad@gmail.com, kaushkarunarathna@gmail.com developing software. That is the reason for having good market value for the software development industry and IT job role in Sri Lanka as well as in the world.

\section{il. Global Software Development}

As a discipline, global software development domain is complemented well by practices that affect research and by the best practices as well. However, for this domain to be a well-established discipline, there is still considerable knowledge of the methods and techniques to be developed, and also more practices to be developed. The main goal of this paper is to study the influence of technical, personal, educational, and general competencies on the expectations of employers in individual and teamwork settings. Although there are obstructions and challenges of managing software development in an international scale, the growth of this area is astounding. The international development software domain seems to be an integral component for companies for several reasons, including economic reasons, such as the overheads and resources, and the need to improve customer service. Since it is fast becoming prevalent in business, valid plans of action are needed, to organize and manage global software development. With the growth of globalization and the further development of distributed software development around the world, the engineering and management practices need to be better clarified, to gain fruitful results in global software development. Also, with time, the methods and systems related to the organization and management of global software development have been improved, and with this development, new and useful practices have proceeded to arise.

\section{IT Job Role and Value}

Technology makes the world more connected than yesterday, and it integrates the global activities at a blink of an eye. In the IT sector there are several job roles as identify under software development. These job roles have different duties and tasks which needs specific skills of industry expertise. It is considered to be a full technological era where everything anyone ever need is in the distance of a fingertip. New opportunity seekers do not think what kind of things they do; they think how to adapt technologies and produce a 
technological solution for customers. Not only for customers but company also try to familiarize field of technology for their company because company can reduce their wastage and they can improve past production and can produce quality products. Despite of the sector, each company needs the help of IT in which IT employment value always grow up and have high demand always. As well as according to the value chain previous time IT is the supporting activity, but now IT is key activity globally where it demonstrates the need of individuals with IT knowledge to move with this technology trend.

Different kind of IT Jobs can be identified in regarding with software development sector such as software engineers, developers, quality assurance, project managers, and information security managers, etc. It is a well-known fact that if applicants have good knowledge in IT, they have higher demand to be employed because employers needed clever individuals who will run their projects without any difficulties where eventually employment value for IT is very high as well as IT employee have good salaries and have good opportunities to do their own business in this world. If they have good ideas and IT knowledge, they can start their own business. Therefore, if someone knows IT, they have more value in the world, and they can create it themselves. When Considering world best companies it is easy to identify that most of them are IT companies such as Facebook, Amazon, Google.

Apart from that, salary scales for IT employees is high as well as the opportunities they have. Turn an idea into a business is very common in the IT sector like Facebook, Amazon, Google, etc. Countries like Denmark, Switzerland, Canada, Australia has a high demand for software engineer developers and IT employees as well as they can apply for citizenship if they want to. It shows that IT employee has more capital intensive in the world. In the current situation, IT companies and non-IT companies hire more IT audit employees to their company. Since security is given the priority in global companies, try to secure their data and information from the world. As a result, companies hire most of information security managers as employees and increase cyber-security of it. Consequently, IT security managers have more demand in the IT industry. It is very vibrant that the value of IT-related jobs are enhancing day by day along with the technology where it shows how fast this industry has grown. Furthermore, Sri Lanka has a prominent IT market value. Therefore, students select IT degree in their higher education as well as foreign organizations outsource their projects to Sri Lankan companies. This is one of a foremost reason to increase Sri Lankan IT market, and it contains project manager, data analyst, quality assurance, software architect, tech-leads, and developers, etc.

Organizations adapt to new technologies frequently. Few decades back IT considered as a support service, yet it became a main component in every organization by adding more benefits as well as competitive advantages to other organizations. According to the study done by (Acuña, Gómez, Hannay, Juristo, \& Pfahl, 2015), individual and teams engaged in the software development process of IT, and ICT companies highly contribute their software development process. Apart from the above, software development process can be identified as a team activity accompanied with the collaboration, coordination and conflicts among the team yet the performance and competencies of the individual are also contribute to the success of the project (Balamohan, Tech, \& Dr.S, 2015).

Because of the industry demands, various skills and competencies from the graduates and also the demanding skills and competencies will be differentiating according to the teamwork setting and individual work setting. There were studies conducted in different environments studying about graduate skills and what employer expect (McMurray, Dutton, McQuaid, \& Richard, 2016; Md Saad, 2014; Stevens \& Norman, 2016) yet the employers' expectations of how these skills affect the performance of the employee when employed individual and in a group has not been observed completely in Sri Lankan context. In that case, this study is focused on examine the influence of technical, personal, educational, and general competencies of new employees holding an IT degree to draw differences between individual and teamwork settings.

\section{Literature Review}

The world is always changing with technology and innovations. Because "of this rapidly changing technology, globalized markets and new modes of work organizations, there is high demand for IT staff with multiple and hybrid skills profile" (Paguio, 2016). It is not a undisclosed matter any longer that there is a shortage of professional IT skilled people out there all over the world. With the increase of new technology advances, the competitiveness is also increasing. Henceforth employers prefer to hire people who are IT, experts. There are different techniques, that can measure the skills of candidates, and numerous researches have been done throughout the time concerning employers' expectations of the capabilities of employees/ graduates/ undergraduates in the IT industry. Initially, prior to looking at the employer's expectations of graduates, specifically in the industry of IT software development, the role of higher education in this regard has to be understood. Institutes engaged in tertiary education often seek to apply practical aspects of a subject to the theoretical work, included in a curriculum, to best prepare the students enrolled in higher education for their eventual release into the real world experience as employees. The rate of employability of 
graduates from a university, as reflected from employer's feedback, is a factor that induces a higher education institutes' reputation (Shah, Grebennikov, \& Nair, 2015) and therefore, conversing with the industry professionals and incorporating information from the industry to the subject work is an essential aspect in higher education (Osmani et al., 2015). Although this is the case, oftentimes, more focus is given by students towards grades and academic performance, mainly focusing on the improvements to their grade point averages (GPA). Good academic work will best prepare students in regards to placement tests (Andrews \& Higson, 2008) and are sought after by employers in selecting graduates as suitable employees (Belwal, Priyadarshi, \& Al Fazari, 2017; Chhinzer, 2018). Although educational success is an extremely important element in graduates, some of the other essential factors that have been perceived by employers as the most suitable attributes are factors that are more practical, as opposed to theoretical information, for a workplace. Some of them are interpersonal and communication skills, social skills, leadership, being team players and, in the case of IT related jobs, the technical skills (Aasheim, Williams, \& Butler, 2009; Hernández-March, Martín del Peso, \& Leguey, 2009; Jackson, 2014; Mardis et al., 2018). Therefore, higher education institutes and mediums must ensure to recognize these components and practice embedding them to the students' academic activities for better preparation (Jackson, 2012). Because of the expansion of higher education that has occurred with enrolment of a large number of students, and since there are many avenues and options to evaluate and choose in the case of higher education, it is important to look at the gaps that exist between the industry specialists' expectations and graduates that leave the institutes in order to stay competitive and provide the best education compared to other avenues (Nicolescu, Păun, \& Management, 2009; Shah et al., 2015).

Prior to looking at the specific domain of this study, that is the software development industry, the findings from researches looking into other specialization or general areas will be looked at, to broadly identify the gaps between the employers' perceived competencies that a graduate should have versus what skills and knowledge graduates actually have.

There are many existing studies that have looked at graduates' competencies and employability in other countries, especially within Australia, which was confirmed by Osmani, et al.(2015) after the review of 39 papers in the areas of management, accounting and computer science. However, there are multiple articles that have focused on graduates' attributes and employability from a range of different countries within different time periods. In the meantime in Spain, Hernández-March, et al.(2009) carried out a research to firstly identify the required competencies from university graduates as demanded by the labor market, and secondly to find out the mismatches that may exist between the current higher educational students receive and company demands; third, to look into minimizing the gap that exists between the current level of education of the graduates and the business need, as recognized by employer, so that higher education institutes can seek to reduce this lacuna through improvements to the curriculum. The objectives of the aforementioned study was done through mixed methods, using 4 in-depth interviews and questionnaires targeting 872 companies surveyed from a database of the 5000 main Spanish companies and respectively they have divided the competencies under vocational competencies and generic competencies (knowledge related skills, methodological skills, and interpersonal skills) and subsequently the results of the study showed that employers value the most in graduates are technical field specific knowledge as well as interpersonal skills. Furthermore Jusoh (2011) investigated in expectation gaps, job satisfaction, and organizational commitment of fresh graduates to reveal the difference between what fresh graduates expect and their experiences pertaining to the working environment, by using self-administered questionnaires. This study was in the view of graduates after employment. The data was collected from 128 graduates, and they were asked to indicate their preferences on organizational culture, leadership, communication, decision making, team working, motivation and development, the results indicate that significant expectation gap exists in all the areas surveyed. Focusing on both the graduates and employers' perspectives of the necessary level of skill that the graduates as employees must have, it was revealed that there is a disparity that explained the role that higher education plays in teaching the software needed in the financial services sector (Tickle, Kyng, \& Wood, 2014). This study, through an in-depth online survey, was carried out in Australia, but the applicability was common globally since the practices of the financial services sector are often common around the world. This study of Tickle, et al. (2014) found that the disparity could be due to the less formal training in the workplace or also due to proper and effective learning opportunities were unavailable during higher education. This is serious accusation to higher education from a workplace that heavily utilizes the software for productive work. For the purpose of examining the difference between fresh graduates' expectations and actual experiences regarding work environment Islam (2015) conducted a research which evaluated using a questionnaire where 170 Malaysian graduates were questioned, and results indicate that there are gaps concerning what fresh graduates expect and their actual experience regarding work environment and apart from that leadership communication and decision making 
was found to be significantly related with job satisfaction whereas leadership was found to be related with organizational commitment. Another study within the Malaysian context of graduate employability by Cheong, Hill, Fernandez-Chung, \& Leong (2016) stressed that there are discrepancies with the expectations and realities with Malaysian graduates and that while they are "far from ideal", there are certain strengths that come from these graduates such as "familiarity with local conditions", being willing to work effortlessly, and agreeing to work for inferior hiring costs in comparison to graduates from other countries. McMurray, et al.(2016) examined on what employers demand for business and management skills in the Scottish workforce by using 71 employers as a sample where

they have found that the factors that are important in recruiting graduates according to employers were; personal attitude, employability skills, relevant work experience, degree result and the most important transferable skills to employers when recruiting graduates were; trustworthiness, ability to be relied on, motivation, ability to communicate well and being willing to learn. In order to explore the most common graduate attributes as they apply to graduates' employability in Oman, Past three cohorts of graduates from a prominent university in Oman were interviewed by using both focus group and survey approach and Belwal, et al.(2017) conclude that the domain of educational institutions in Oman were mainly restricted to the basic generic skills in developing the graduates' attributes, as well as students' perspectives on employers selection criteria revealed that computing skills, the ability to work in teams, proficiency in English language, prior training and the personality of the graduates are the five most significant employability skills in Oman. Chhinzer (2018) came to the field in order to explore employer perceptions of graduate student employability and using a two-phased approach, the authors analyzed 122 employers' assessments of graduate students at a Canadian university who completed a work term with the employer in either 2014 or 2015 and authors collected individual data from student files at the university which lead to demonstrate qualities such as "professional maturity, soft skills, problem solving, continuous learning and academic achievement" had a positive relationship with employer perception of graduate employability. It also indicates that employers consider generic skills, general - mental ability, subject specific knowledge, willingness to work, attitudes and behaviors, responsiveness to feedback when assessing the employability of graduate students.

Looking at employers' perceptions of graduates, finding from beyond the skill levels of graduates have been researched, focusing on postgraduates. These studies have revealed almost similar results in what the employers expect from graduates and will be important since graduates at their current level itself can progress better by grasping the attributes expected at the post-graduate level. In 2001, a research was conducted in Malaysia to evaluate employers' general perception on the recruitment and work attributes of executives with MBA Degrees. In a survey of 500 employers throughout Malaysia, Tay (2001) have found that managers do recognize the contribution of MBAs based on their positive work attributes by investigated on communication skills, analytical skills, Creative and innovative skills in this study and subsequently the results indicated that MBAs with good work ethics, sound management and leadership skills, critical thinking and analytical abilities have more chances to be hired. According to Martensen (2009), they have focused on measuring competencies of higher education graduates and employers' needs, and they have studied the Danish employers' perceptions of MSc graduates from Copenhagen Business School by interviewing 250 employers regarding professional competencies, personal and social competencies, and also they have concluded that the business industry advertises for improved professional competencies of a more general commercial character; below areas should be improved;

- Ability to create results,

- Business knowledge,

- Communication skills (ability to communicate with other people), and

- Application of theoretical knowledge.

This review broadly looked at the overall scope of graduate attributes in different areas. However, the requirements of specific industries can differ from one another. Therefore, as per the research objectives, the employers' perceptions of IT graduates attributes must be considered. Firstly, it must be identified that the software development industry drives on the development and importance of ICT that has grown over the years. Gerhan \& Mutula (2007) focused on a model that shows how ICT is used, and it proposed that ICT is a "commodity, supporting development activity, driver of the economy" and can be "directed at specific development projects". Applying this model to a university showcased the importance of ICT to create knowledge workers.

Furthermore, literature shows a significant research that was conducted in Turkey to investigate employers' performance expectations for new IT graduates in individual and teamwork settings for software development by using a survey approach of 110 employers and study revealed that significant diversity exists in individual and teamwork setting regarding employers' expectations for new graduates' competencies in terms of adapting to new software development methods and approaches, using time effectively and experiences gained in undergraduate projects (Akman \& Turhan, 2018). 
The findings and results from the reviewed literature revealed the identification of the gaps between the employers' expectations and the competencies that graduates must possess is vital in order to bridge them to create the most workable environment for new IT graduates. This means that the graduates can work on getting rid of the aspects of a job that can create an initial reality shock from the formal setting, which should be facilitated by their higher education as well (Vilapakkam Nagarajan, 2014). Considering the research area, there is a clear lacuna of studies that have considered the employer's expectation of IT graduates in the software development industry in the Sri Lankan context. Therefore, this research will consider some of the most sought after competencies that were identified by IT specialists. They can be categorized as the technical, personal, general competencies and looking at these competencies according to two main settings, that is the individual setting and in teamwork settings. Accordingly, these factors will drive the research in creating the theoretical framework and methodologies which will reveal the employer's perceptions of the competencies of new IT graduates in the Sri Lankan software development industry, which will provide the findings to answer the research questions, according to the hypothesized factors and achieve the objectives of this research.

\section{Hypothesis of the Research}

As the study based on the industry software development, It is a well-known factor that most of the time there are works to do as a team and the success of the project depends on the teamwork and competencies that employees own individually. Furthermore Akman \& Turhan (2018) stated that there is a significant difference in the expectations of employees when it comes to the technical, personal, and educational, competencies of their employees who newly graduated from IT stream in individual and teamwork settings. In accordance with current literature, competencies put into four categories.

\section{a) Technical competencies}

To perform effectively in a specific job in an organization employees need to have exact knowledge and skills, those skills can identified as technical skills. And there are several researches have been conducted to examine the gap between employer perception and graduates technical competencies. Developing technical competencies during undergraduate education considered to be a significant element for employability in the industry (Nair, Patil, \& Mertova, 2009). And Akman \& Turhan (2018) indicate that technical skills are more essential than organizational and managerial skills. As mentioned before competencies were grouped under four categories, under technical category authors will be considering SD processes, SD methods, SD solutions, Adaptability, and Situation Monitoring (refer figure). All these findings show that between technical competencies and employers' expectations for different work sittings can be further investigated. Therefore following hypotheses are going to be tested.

H1tx - Observed technical competency of the new graduate that holds an IT degree has a significant impact on expectations of an employer in individual work settings.

H1ty - Observed technical competency of the new graduate that holds an IT degree has a significant impact on expectations of an employer in teamwork settings.

\section{b) Personal competencies}

There are many personal attributes that decide employee performance and directly impact to the organization. Mukhtar, et al. (2009) researched to measure the relationship between personal competencies and employability and results indicate that there is a lack of competencies among university graduates in communication, leadership and time management. As well as research emphasize that importance of working in different work settings too. To conduct this study, we are going to investigate skills in communication, leadership, time, creative thinking, and mutual Support under personal competencies category. In that case, it is important to properly investigate employers' perception about personal competencies in individual and teamwork settings (refer figure 1). Therefore, the following hypotheses are proposed.

H2px - Observed personal competency of the new graduate that holds an IT degree has a significant impact on expectations of an employer in individual work settings.

H2py - Observed personal competency of the new IT graduate that holds an IT degree has a significant impact on expectations of an employer in teamwork settings.

\section{c) Educational competencies}

In a study conducted by Akman \& Turhan (2018) contrasted that there is an influence on involving different work settings can be different according to the course-based and senior year graduation projects. And also they have found that literacy in the English language has as the highest demand by employers. In this study on the education competencies, authors are going to investigate on language skills, projects, accreditation, knowledge of business fundamentals, and work ethics (refer figure 1). Even if these competencies were tested before, there is a need for more surveys to increase the validity of the items used in measuring employability in terms of different works settings so that authors of formulating the following hypotheses. 
H3ex - Observed educational competency of new graduate that holds an IT degree has a significant impact on expectations of an employer in individual work setting.

H3ey - Observed educational competency of new graduate that holds an IT degree has a significant impact on expectations of an employer in teamwork setting.

\section{d) General Competencies}

Apart from the above competencies, employers are looking for competencies despite the degree such as problem solving, self-management, accountability, interpersonal skills, and knowledge of business trends. Mardis, et al. (2018) researched technology educational opportunities, professional requirements, and industry demands, and tested on general competencies of employees and discovered that the internship postings importantly emphasized technical competencies over general competencies (refer figure 1).

Even if these competencies were tested before, there is a requirement for additional reviews to increase the validity of the items used in determining employability in terms of different works settings so that authors of formulating the following hypothesis.

H4ex - Observed general competency of new graduate that holds an IT degree has a significant impact on expectations of an employer in individual work setting.

H4ey - Observed general competency of new graduate that holds an IT degree has a significant impact on expectations of an employer in teamwork setting.

\section{Research Design and Methodology}

Authors are doing explanatory research, which is an effort to link concepts to understand cause and effect. To bond the gap among performance expectations of an industry for new IT graduates in software development in Sri Lankan context, a conceptual framework was designed using past literature in which it describes independent and dependent variables indistinctly. The questionnaire of this study supported by mentioned variables where it distributed among IT professionals to gather relevant data. With the intention of identifying the expectations of employers on the technical, personal, educational, and general competencies of an employees, holding an IT degree and to draw differences between individual and teamwork settings, the research design of this study is carried out.

In this investigation, authors have used judgmental sampling technique where it identified as non-probability sampling technique, which depends based on the judgment of research team. The previous studies which similar to this study are frequently led by researchers had conveniently selected judgmental sampling technique (Akman \& Turhan, 2018). Consequently, this technique of sampling was taken.

An entire sample of 120 employers from software development industry was surveyed to identify the expectations of employers on the technical, personal, educational, and general competencies of employees, holding an IT degree and to draw differences between individual and teamwork settings in software development industry through judgmental sampling though total of 112 survey questionnaires were used after removing outliers, demonstrating 93.3\% of response rate. Priority was given to the participants who are working software development industry as professionals when choosing respondents.

This section specifies how the proposed methodology is used to analyze the expectations of employers on the technical, personal, educational and general competencies of employees that holding an IT degree to draw differences between individual and teamwork settings. The complete study was aligned on a conceptual framework, which has six (6) variables which will be discussed further.

The Conceptual framework is the investigator's understanding of how specific variables in the study link with each other. As a result, it recognizes the variables vital in the research investigation. According to the conceptual framework of this study, authors have identified six (6) variables as technical competencies, personal competencies, educational competencies, general competencies, individual work expectations, and teamwork expectations. When reviewing the past literature, Akman and Turhan (2018) had used technical, personal and educational competencies in their study and authors of the current study expand the conceptual framework by reviewing other past literature such as (Paguio, 2016; Tay, 2001). To achieve the objective of the study, to ascertain the expectations of employers on the technical, personal, educational, and general competencies of employees, holding an IT degree and to draw differences among individual and teamwork settings according to the identified competencies. Here technical, personal, educational and general competencies act as independent variables and individual and teamwork settings act as dependent variables. 


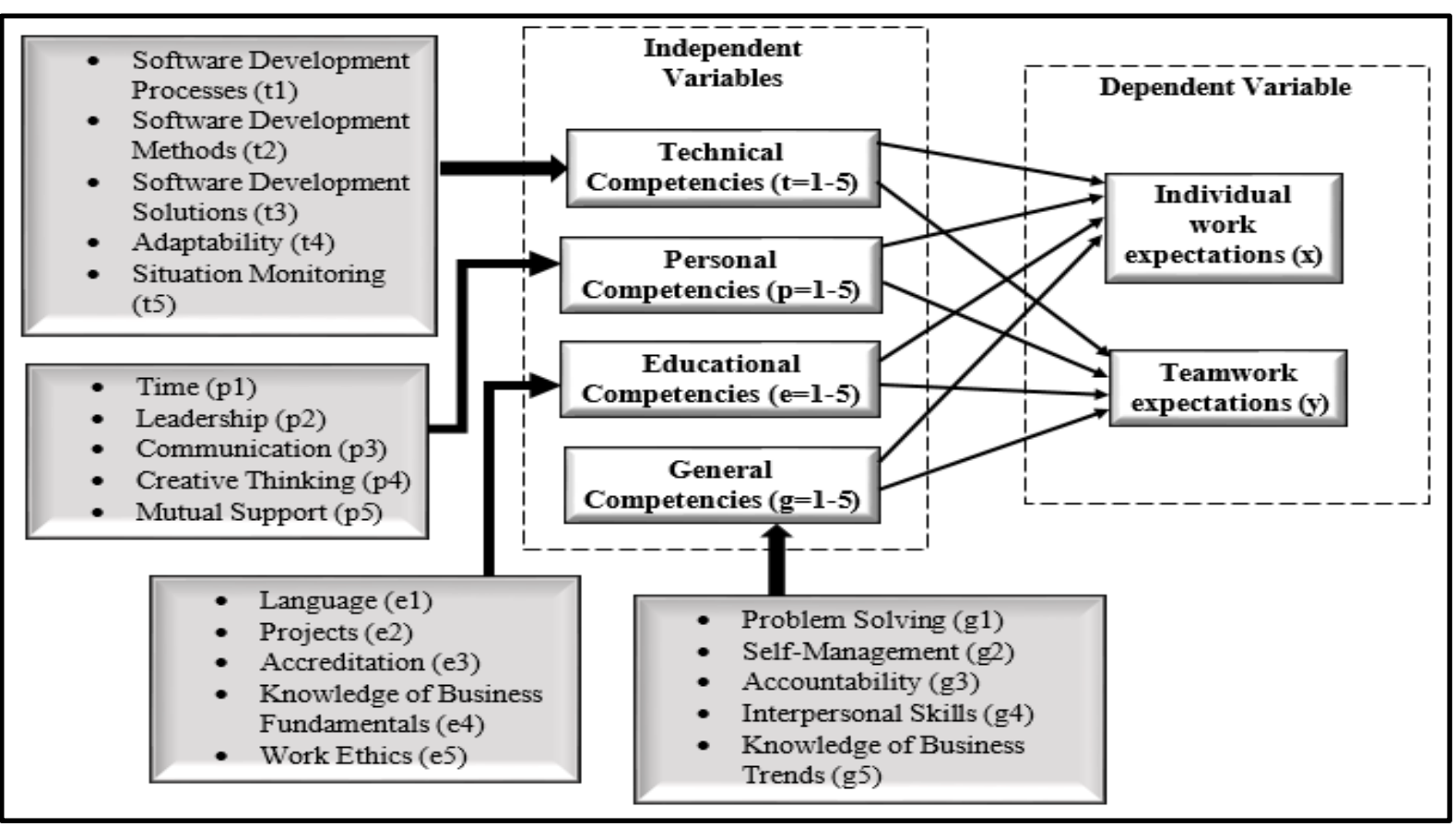

Source: Based on (Akman \& Turhan, 2018)

\section{Figure 1: Conceptual Framework}

\section{Vil. Descriptive Results}

From the table 1, a comprehensive analysis of the set of respondents with concerning their current position in the industry can be contrasted. From a total of 112 respondents, a majority (30.36\%) is tech Leads (34). Count of IT unit/project managers and senior software developers is 25 each. That is $22.32 \%$ of the total number of respondents. There are 17 Senior IT professionals leaving only 11 information security managers. That can be justified by the fact that Sri Lanka does not employee enough Information security managers in the IT industry. The distribution of these respondents in the sectors of public, private and semiGovernment a clear majority is in the private sector. That is 105 out of $112(93.75 \%)$ leaving only $5(4.46 \%)$, and 2 $(1.79 \%)$ from the sectors of public and semigovernment. This might not reflect the distribution of management level employees in the IT industry of Sri Lanka, but gives a hint about the general distribution in the three sectors. Since public and semi-government sectors' respondent count is very little, the private sector's respondent distribution by designation is roughly equal to the total distribution that discussed earlier. And also, field of study through higher education of the respondents, obviously the majority (90) has studied in the field of IT. That is an $80.36 \%$ of the total. Other $22(19.64 \%)$ is from non IT- related fields of study. Most of the respondents from non-IT related fields of study are in the positions of tech Lead (10) and IT unit/project manager (8). The $\mathrm{X} 2$ test shows that the dependence on the field of study through higher education and their current position is statistically meaningful $(X 2=11.269 ; \mathrm{df}=4 ; \mathrm{p}$-value $=0.024)$. The total distribution by gender is $62.5 \%$ Male to 37.5 Female roughly $2: 1$ ratios. When it comes to experience, there are not many experienced employees in the management level of the IT industry. Most of the employees have experience of less than six (6) years. Employee count reduces drastically with the years of experience. 


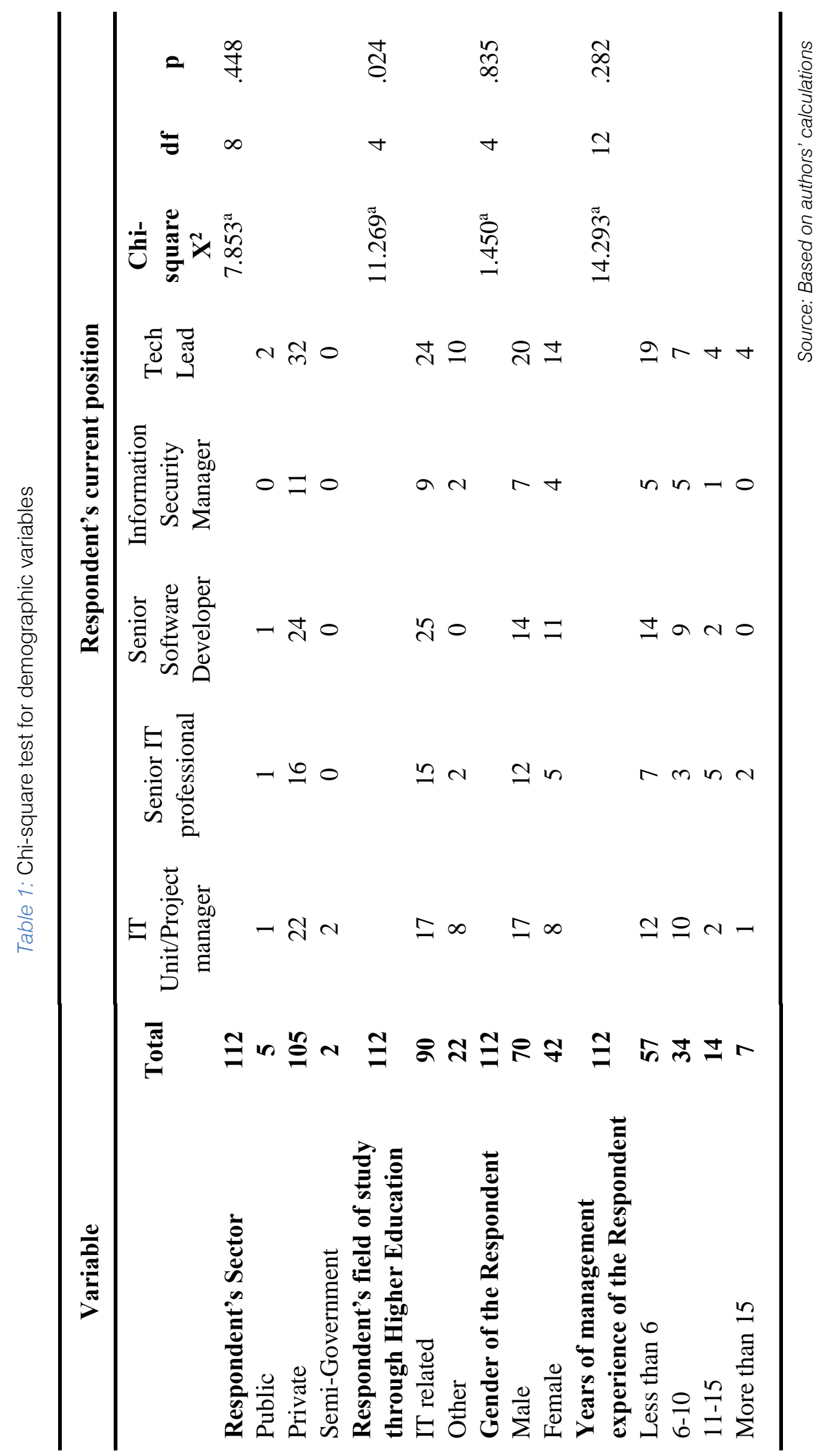


Table 2: Chi-square test for demographic variables

\begin{tabular}{|c|c|c|c|c|c|c|}
\hline \multirow[t]{2}{*}{ Variable } & \multirow[b]{2}{*}{ Total } & \multicolumn{5}{|c|}{$\begin{array}{c}\text { Respondent's field of study through } \\
\text { Higher Education }\end{array}$} \\
\hline & & $\begin{array}{c}\text { IT } \\
\text { related }\end{array}$ & Others & $\begin{array}{c}\text { Chi- } \\
\text { square } \\
\mathrm{X}^{2}\end{array}$ & df & p \\
\hline $\begin{array}{l}\text { Organization's satisfaction } \\
\text { from new graduates }\end{array}$ & 112 & & & $9.242^{\mathrm{a}}$ & 4 & .055 \\
\hline Highly Satisfied & 13 & 9 & 4 & & & \\
\hline Satisfied & 31 & 27 & 4 & & & \\
\hline Average & 36 & 33 & 3 & & & \\
\hline Dissatisfied & 12 & 8 & 4 & & & \\
\hline Highly Dissatisfied & 20 & 13 & 7 & & & \\
\hline
\end{tabular}

Source: Based on authors' calculations

In this study, (from table 2) that most of the respondents' field of study through Higher Education was IT- related. Out of the 112 respondents 90 were related to IT while only 22 was in other fields of study. Out of all 112 respondents, a majority of 36 thinks that the organization's satisfaction from newly graduated employees is average while another 31 thinks the organization is satisfied. A relatively lower number of respondents, 13 and 12 respectively think the organization is highly satisfied and dissatisfied from the new graduates. The responses have a near symmetric distribution within these four responses, but a relatively higher number (20) of responses have been recorded as highly dissatisfied. Hence the symmetric distribution has got biased towards dissatisfaction. If it separate the responses by the respondents 'field of study, almost $1 / 3$ rd of respondents with a non-IT related higher education has responded as highly dissatisfied. The X2 test that the different between the distribution of the organization's satisfaction expectation and the respondent's field of gradation cannot find significance $(\mathrm{X} 2=7.583 ; \mathrm{df}=8 ; \mathrm{p}$-value $=0.448)$.

\section{Vili. Qunantitative Analysis}

For examining the influences of technical, personal, educational and general competencies on the expectations of employers in individual work settings and teamwork settings 23 Likert scale questions were used in which it had 5-point Likert item with $1=$ "Strongly agree" and $5=$ "Strongly disagree."

According to the Spearman correlation tests for the hypotheses, results are representing in table 3.

For the technical competencies, significance value and correlation coefficient values disclose followings:

Individual work settings: There are satisfactory proofs to accept H1t1x and H1t2x at the 0.01 level. And also,
$\mathrm{H} 1 \mathrm{t} 3 \mathrm{x}$ at the 0.05 significance level in the individual work settings. It demonstrates that "SD-processes," "SDmethods" and "SD-solutions" have a statistically significant relationship with individual work settings, which means, employers are definite of the new IT graduates should be competent in the software development processes and should be adoptable to new software development methods and approaches. As well as new IT graduates should be capable of devising solutions to problems. Those are important for individual work settings. Variables "adaptability" and "situation monitoring" were not identified to have a statistically significant relationship with the variable "individual work" settings. Therefore, $\mathrm{H} 1 \mathrm{t} 4 \mathrm{x}$ and $\mathrm{H} 1 \mathrm{t} 5 \mathrm{x}$ were rejected. This finalized that employers are not considering about adopt to changes through work environment and demonstrate initiative to identify and rectify incorrect practices from new IT graduates in individual work settings. 
Table 3: Correlation analysis for variables

\begin{tabular}{|c|c|c|c|c|c|c|c|}
\hline \multirow{2}{*}{$\begin{array}{c}\text { Empirical } \\
\text { Factor }\end{array}$} & \multirow[b]{2}{*}{ Test Variables } & \multicolumn{3}{|c|}{ Individual Work (IW) } & \multicolumn{3}{|c|}{ Team Work (TW) } \\
\hline & & Нyp. & Coeff. & $\rho$-val. & Hyp. & Coeff. & $\begin{array}{l}\rho- \\
\text { val. }\end{array}$ \\
\hline \multicolumn{8}{|l|}{ Technical } \\
\hline \multicolumn{8}{|l|}{ Competencies } \\
\hline & SD-processes & $\mathrm{H}_{1} \mathrm{t} 1 \mathrm{x}$ & $0.327 * *$ & 0.000 & $\mathrm{H}_{1} \mathrm{t} 1 \mathrm{y}$ & $0.449 * *$ & 0.000 \\
\hline & SD-methods & $\mathrm{H}_{1} \mathrm{t} 2 \mathrm{x}$ & $0.336 * *$ & 0.000 & $\mathrm{H}_{1} \mathrm{t} 2 \mathrm{y}$ & $0.294 * *$ & 0.002 \\
\hline & SD-solutions & $\mathrm{H}_{1} \mathrm{t} 3 \mathrm{x}$ & $0.203 *$ & 0.032 & $\mathrm{H}_{1} \mathrm{t} 3 \mathrm{y}$ & $0.262 * *$ & 0.005 \\
\hline & Adaptability & $\mathrm{H}_{1} \mathrm{t} 4 \mathrm{x}$ & 0.150 & 0.115 & $\mathrm{H}_{1} \mathrm{t} 4 \mathrm{y}$ & $0.197 *$ & 0.038 \\
\hline & Situation monitoring & $\mathrm{H}_{1} \mathrm{t} 5 \mathrm{x}$ & 0.160 & 0.093 & $\mathrm{H}_{1} \mathrm{t} 5 \mathrm{y}$ & 0.129 & 0.176 \\
\hline \multicolumn{8}{|l|}{ Personal } \\
\hline \multicolumn{8}{|l|}{ Competencies } \\
\hline & Time & $\mathrm{H}_{2} \mathrm{p} 1 \mathrm{x}$ & -0.042 & 0.663 & $\mathrm{H}_{2} \mathrm{p} 1 \mathrm{y}$ & -0.042 & 0.662 \\
\hline & Leadership & $\mathrm{H}_{2} \mathrm{p} 2 \mathrm{x}$ & $0.219 *$ & 0.020 & $\mathrm{H}_{2} \mathrm{p} 2 \mathrm{y}$ & 0.158 & 0.096 \\
\hline & Communication & $\mathrm{H}_{2} \mathrm{p} 3 \mathrm{x}$ & 0.036 & 0.706 & $\mathrm{H}_{2} \mathrm{p} 3 \mathrm{y}$ & 0.092 & 0.332 \\
\hline & Creative thinking & $\mathrm{H}_{2} \mathrm{p} 4 \mathrm{x}$ & 0.044 & 0.647 & $\mathrm{H}_{2} \mathrm{p} 4 \mathrm{y}$ & 0.117 & 0.218 \\
\hline & Mutual Support & $\mathrm{H}_{2} \mathrm{p} 5 \mathrm{x}$ & 0.111 & 0.244 & $\mathrm{H}_{2} \mathrm{p} 5 \mathrm{y}$ & -0.023 & 0.809 \\
\hline \multirow{2}{*}{\multicolumn{8}{|c|}{$\begin{array}{l}\text { Educational } \\
\text { Competencies }\end{array}$}} \\
\hline & & & & & & & \\
\hline & Language & $\mathrm{H}_{3} \mathrm{e} 1 \mathrm{x}$ & $0.204 *$ & 0.031 & $\mathrm{H}_{3} \mathrm{e} 1 \mathrm{y}$ & 0.144 & 0.129 \\
\hline & Project & $\mathrm{H}_{3} \mathrm{e} 2 \mathrm{x}$ & $0.194 *$ & 0.040 & $\mathrm{H}_{3} \mathrm{e} 2 \mathrm{y}$ & 0.162 & 0.088 \\
\hline & Accreditation & $\mathrm{H}_{3} \mathrm{e} 3 \mathrm{x}$ & 0.101 & 0.291 & $\mathrm{H}_{3} \mathrm{e} 3 \mathrm{y}$ & -0.006 & 0.949 \\
\hline & Know. of Busi. Fund. & $\mathrm{H}_{3} \mathrm{e} 4 \mathrm{x}$ & 0.171 & 0.071 & $\mathrm{H}_{3} \mathrm{e} 4 \mathrm{y}$ & 0.159 & 0.095 \\
\hline & Work Ethics & $\mathrm{H}_{3} \mathrm{e} 5 \mathrm{x}$ & 0.077 & 0.419 & $\mathrm{H}_{3} \mathrm{e} 5 \mathrm{y}$ & 0.165 & 0.082 \\
\hline \multirow{2}{*}{\multicolumn{8}{|c|}{$\begin{array}{l}\text { General } \\
\text { Competencies }\end{array}$}} \\
\hline & & & & & & & \\
\hline & Problem Solving & $\mathrm{H}_{4} \mathrm{~g} 1 \mathrm{x}$ & -0.107 & 0.262 & $\mathrm{H}_{4} \mathrm{~g} 1 \mathrm{y}$ & 0.120 & 0.209 \\
\hline & Self-Management & $\mathrm{H}_{4} \mathrm{~g} 2 \mathrm{x}$ & -0.004 & 0.964 & $\mathrm{H}_{4} \mathrm{~g} 2 \mathrm{y}$ & 0.157 & 0.098 \\
\hline & Accountability & $\mathrm{H}_{4} \mathrm{~g} 3 \mathrm{x}$ & -0.018 & 0.851 & $\mathrm{H}_{4} \mathrm{~g} 3 \mathrm{y}$ & 0.097 & 0.307 \\
\hline & Interpersonal Skills & $\mathrm{H}_{4} \mathrm{~g} 4 \mathrm{x}$ & 0.056 & 0.557 & $\mathrm{H}_{4} \mathrm{~g} 4 \mathrm{y}$ & 0.271 & 0.004 \\
\hline & Know. of Busi. Trends & $\mathrm{H}_{4} \mathrm{~g} 5 \mathrm{x}$ & 0.041 & 0.671 & $\mathrm{H}_{4} \mathrm{~g} 5 \mathrm{y}$ & 0.081 & 0.393 \\
\hline
\end{tabular}

Teamwork settings: In this category, "SD-processes," "SD-methods," SD-solutions" are having a statistically significant relationship with teamwork settings at the 0.01 level. And also, variable "adaptability" is having a statistically significant relationship with teamwork settings at 0.05 level. Therefore, H1t1y, H1t2y, and $\mathrm{H} 1 \mathrm{t} 3 \mathrm{y}$ were accepted at 0.01 significant level. $\mathrm{H} 1 \mathrm{t} 4 \mathrm{y}$ was accepted at 0.05 significant level. This states that new IT graduates should be competent in the software development processes, adoptable to new software development methods and approaches, capable in devising solutions to problems, adapt to changes through work environment in teamwork settings. This category found only on a variable that there is no statistically significant relationship with a teamwork setting. The variable is "situation monitoring," and this demonstrates that employers are not expecting new IT graduates to indicate initiative to identify and rectify incorrect practices. Therefore, $\mathrm{H} 1 \mathrm{t} 5 \mathrm{y}$ was rejected.

Comparison: As stated by the results, "SDprocesses," "SD-methods," "SD-solutions" are significant for both individual and teamwork settings. The variable "adaptability" is insignificant for the individual work settings and significant for the teamwork settings. But the variable "situation monitoring" is insignificant for both individual and teamwork settings in technical competencies.

For the personal competencies, significance value and correlation coefficient values disclose followings:

Individual work settings: The only variable that found to have a significant relationship with individual work settings in personal competencies is "leadership" at the 0.05 significant levels. Therefore, H2p2x was accepted. 
This states that the new IT graduates must possess leadership skills. All other variables "time," "communication," "creative thinking," and "mutual support" have found to be an insignificant relationship with individual work settings in personal competencies. Consequently, H2p1x, H2p3x, H2p4x, H2p5x were rejected. This indicates that employers do not expect new IT graduates to manage time effectively, to be excellent communicators, ability to come up with new ideas and how the system operates and work accordingly.

Teamwork settings: There are satisfactory proofs to reject all the hypotheses in teamwork settings for personal competencies. These contrasts that employers believe new IT graduates manage time effectively, leadership skills, excellent communications, ability to come up with new ideas and how system operates and work accordingly are not required in the teamwork settings for personal competencies. Hence, H2p1y, H2p2y, H2p3y, H2p4y, and H2p5y hypothesis are rejected.

Comparison: Considering the above results, "leadership" is the only variable that having a significant relationship with the individual work settings for personal competencies but insignificant with teamwork settings. All other variables are insignificant in both individual and teamwork settings.

For the educational competencies, significance value and correlation coefficient values disclose followings:

Individual work settings: Variables "language" and "projects" are having a statistically significant relationship with individual work settings at the 0.05 significant level. Therefore, $\mathrm{H} 3 \mathrm{e} 1 \mathrm{x}$ and $\mathrm{H} 3 \mathrm{e} 2 \mathrm{x}$ hypothesis accepted. This yields that employers consider the new IT employees graduated from a university adopting English as the medium, and new IT graduated employees worked in a project during their university education. But other variables "accreditation," "knowledge of business fundamentals," and "work ethics" are insignificant with the individual work settings. That means, university accredited by the UGC (University Grant Commission), know underlying business concepts like debt, cash flow, supply, and demand for company products that effect business operations, to have good work ethics are do not consider as important in the individual work settings. Therefore, $\mathrm{H} 3 \mathrm{e} 3 \mathrm{x}, \mathrm{H} 3 \mathrm{e} 4 \mathrm{x}$ and $\mathrm{H} 3 \mathrm{e} 5 \mathrm{x}$ hypotheses are rejected.

Teamwork settings: According to the above results, all hypotheses H3e1y, H3e2y, H3e3y, H3e4y, and H3e5y are rejected in the teamwork settings. Variables "language," "project," "accreditation," "knowledge of business fundamentals," and "work ethics" are insignificant with teamwork settings. This states that employers do not consider importantly English as the medium, projects during university education, accredited by the UGC, knowledge of business fundamentals, to have good work ethics in teamwork settings.

Comparison: "Language" and "projects" are two variables that have a significant relationship with the individual work settings but insignificant with the teamwork settings. All other variables are insignificant with both individual and teamwork settings.

For the general competencies, significance value and correlation coefficient values disclose followings:

Individual work settings: There is satisfactory evidence to reject hypotheses $\mathrm{H} 4 \mathrm{~g} 1 \mathrm{x}, \mathrm{H} 4 \mathrm{~g} 2 \mathrm{x}, \mathrm{H} 4 \mathrm{~g} 3 \mathrm{x}, \mathrm{H} 4 \mathrm{~g} 4 \mathrm{x}$, and $\mathrm{H} 4 \mathrm{~g} 5 \mathrm{x}$. Because variables "problem solving," "selfmanagement," "accountability," "interpersonal skills," and "knowledge of business trends" are insignificant with the individual work settings. This indicates that, employers do not consider being work through details of a problem to reach a comprehensive solution, selfmanagement skills that help an employee to feel and be more productive in the workplace, complete the tasks they are assigned, self-esteem, interpersonal skills, to have sound knowledge on current business trends as vital in the individual work settings.

Teamwork settings: There are satisfactory evidence to reject hypotheses H4g1y, H4g2y, H4g3y, H4g4y, and H4g5y. Because variables "problem solving," "selfmanagement," "accountability," "interpersonal skills," and "knowledge of business trends" are insignificant with teamwork settings. This indicates that, employers do not consider being work through details of a problem to reach a comprehensive solution, self-management skills that help an employee to feel and be more productive in the workplace, complete the tasks they are assigned, self-esteem, interpersonal skills, to have sound knowledge on current business trends as essential in the teamwork settings.

Comparison: This yields that general competencies do not have a significant relationship with the individual work settings and teamwork settings.

\section{Discussion}

Before looking at the specific domain of this study, that is the software development industry, the findings from researches looking into other specialization or general areas will be looked at, to broadly identify the gaps between the employers' perceived competencies that a graduate should have versus what skills and knowledge graduates have. Looking at employers' perceptions of graduates, finding from beyond the skill levels of graduates have been researched, focusing on post-graduates. These studies have revealed almost similar results in what the employers expect from graduates and will be vital since graduates at their current level itself can progress better 
by grasping the attributes expected at the postgraduate level.

However, looking into the transition from a graduate to an IT person was looked at by Clark, Zukas, and Lent (2011) through a three-year longitudinal study, interviewing respondents through in-depth interviews. It revealed that the transition from undergraduate engaged in studying IT into a graduate working in the IT profession, based upon graduate credentials and employability skills is not a straightforward way to look at the transition, but that individual initiative taken for the work is also an important component. It saw that each individual had their own experience into the change, which is an indication of the personal competencies and attributes playing a part in graduates' work life.

In 2001, research was conducted in Malaysia to evaluate employers' general perception on the recruitment and work attributes of executives with MBA Degrees. In a survey of 500 employers throughout Malaysia, Tay (2001) have found that managers do recognize the contribution of MBAs based on their positive work attributes by investigated on communication skills, analytical skills, creative and innovative skills in this study. Subsequently the results indicated that MBAs with good work ethics, sound management, and leadership skills, critical thinking and analytical abilities have more chances to be hired.

The findings of the study show that employers' point of view, technical competencies for example competent in the software development processes and adaptable to new software development methods and approaches are an influence on both individual and teamwork settings. Comparable to this result, another study was conducted in turkey by Akman and Turhan (2018) found that new IT graduated employees should be competent in software development processes and software development methods that significantly related to individual and teamwork settings. But from this study, another result was found that software development solution is significant related with both settings which are individual and teamwork settings. This finding is struggled with previous research which was done by Akman and Turhan (2018) because they found that new IT graduates should not be capable of devising solutions to problems in both individual and teamwork settings. And also, research done by Nair et al. (2009) was found that being flexible and adoptable as the graduate capability. According to this study, results yield that new IT graduates should be able to adapt to changes through the work environment only in teamwork settings. This states that new employees should be flexible and adoptable when working as a team. In proportion to this result, situation monitoring is having an insignificant relationship with individual work settings as well as teamwork settings. This result is a conflict with previous findings because they found that situation monitoring as a teamwork competency which means, when working as a team, new IT graduates should demonstrate initiative to identify and rectify incorrect practices (Paguio, 2016).

For the personal competencies, the finding of this study states that "leadership" is the only variable which is having a significant relationship with individual work settings. But that is insignificant with teamwork settings. This demonstrates that employers are expecting new IT graduates to possess leadership skills only in individual work settings but not in teamwork settings. Akman and Turhan (2018) found that "leadership" as an insignificant variable with both work settings which are individual and teamwork settings. Therefore, this finding is a conflict with previous research. Apart from that they found that, the variable "time" as significant with teamwork settings. That means employers are considering the time management in teamwork settings rather than with individual work settings. But in this study, the variable "time" is not significant with the individual and teamwork settings. According to the research done by Akman and Turhan (2018) found that the variable "communication" as the significant with individual and teamwork settings. Compared to this study, it was found that "communication" is not affecting the individual and teamwork settings. And also, the study yields that "creative thinking" and "mutual support" are insignificant with the individual and teamwork settings. The research conducted by Tay (2001) found that "creative thinking" is essential when working as a team. And another study was conducted by Paguio (2016) has found that "mutual support" as a teamwork competency.

For educational competencies, the study found that "language" and "project" are significant with individual work settings but not with the teamwork settings. It yields that employers are expected IT graduated employees should adopt English as the medium during their university education, as well as employees should work in a project during their university education.

Also, there is a study that found "language" as a teamwork competency in Akman and Turhan (2018) study. But "project" as teamwork competency only. Apart from that, for the "accreditation" variable, findings were the same as the prior research done by Akman and Turhan (2018). Variables "knowledge of business fundamentals" and "work ethics" are not affecting for any of these two work settings which are individual and teamwork settings. This means employers are not expecting graduated employees to know underlying business concepts like business debt, cash flow, supply, and demand for company products that effects business operations and do not consider about good work ethics. In the study done by Mardis et al. (2018) had found that "knowledge of business fundamentals" is not much affecting. Research done by Tay (2001) had originated that "work ethics" as an important variable for 
MBA graduates. Findings of this study yield that general competencies are not affecting the individual and teamwork settings.

This section provided a detailed comparison with existing literature and findings of the current study to get an idea for the graduates themselves in selfimproving their skill set as they look forward to a successful career in renowned companies. They will have a better idea about which areas of competencies they should be improving and which competencies will not affect their career success.

\section{Conclusion}

Information Industry is a fast-growing industry in the current economy due to the emerging demand from almost all the other industries. It requires employees with a unique set of skills to match the specific requirements in the field. Once you hired an employee and after he/she starts working on a project, it will be really tough to replace that individual until the project ends. This timeline might span from few months to a few years depending on the nature of the project and the specific job role of the individual. The objective of this study was to identify the expectations of employers on the technical, personal, educational and general competencies of employees that holding an IT degree to draw differences between individual and teamwork settings according to the identified competencies.

This research is an explanatory research in which 23 variables were selected to analyze, and they were categorized into 7 categories as technical competencies, personal competencies, educational competencies, general competencies, individual work setting, teamwork setting and general performance expectations. One hundred and twenty (120) responses were collected through Survey using judgmental sampling method, and eight (8) of them were removed after identifying as outliers. Total of one hundred and twelve (112) responses were analyzed using correlation test to see the relationship between independent and dependent variables and compare them among individual and teamwork settings.

Among technical competencies, software development process, software development methods, software development solutions have a significant relationship with individual work while adaptability was also significant in teamwork setting along with software development processes, software development methods, and software development processes. Only leadership skills were significant in individual setting when considering Personal competencies, and there were no correlation with any skills in teamwork setting at all. Language and project have a significant relationship with Individual work setting, and there are no skills were significant with teamwork setting in educational competencies. According to the results of general competencies, test results contrasted that there are no skills which have significant relationship with either individual work setting or teamwork setting.

Limitations to this study can be identified, such as respondents have a lack of time with their busy work schedules and chances of meeting IT professionals were decreased due to security reasons implied in Sri Lanka lately. Future researchers can increase the sample size as well as go with an In-depth analysis, and using non-linear regression is also possible with this study.

Furthermore, authors believe that, the study will help employers as well as new IT graduated employees to find out which skills need to be tested more as well as which skills need to be improved. It will be an essential guide for the graduates themselves in self-improving their skill set as they look forward to a successful career in a renowned IT company. They will have a better idea about which areas of competencies they should be improving and which competencies will not affect their career success.

\section{REFERENCES RÉFÉRENCES REFERENCIAS}

1. Aasheim, C. L., Williams, S., \& Butler, E. S. (2009). Knowledge and Skill Requirements for it Graduates. Journal of Computer Information Systems, 49(3), 48-53. doi:10.1080/08874417.2009.11645323

2. Acuña, S. T., Gómez, M. N., Hannay, J. E., Juristo, N., \& Pfahl, D. (2015). Are team personality and climate related to satisfaction and software quality? Aggregating results from a twice replicated experiment. Information and Software Technology, 57, 141-156. doi:https://doi.org/10.1016/j.infsof. 2014.09.002

3. Akman, I., \& Turhan, C. (2018). Investigation of employers' performance expectations for new IT graduates in individual and team work settings for software development. 31(1), 199-214. doi: doi:10.1108/ITP-01-2017-0020

4. Andrews, J., \& Higson, H. (2008). Graduate Employability, 'Soft Skills' Versus 'Hard' Business Knowledge: A European Study (Vol. 33).

5. Balamohan, P., Tech, M., \& Dr.S, G. (2015). Emotional Intelligence - Its Importance and Relationship with Individual Peformance, TeamEffectiveness, Leadership and Marketing Effectiveness (Vol. 6).

6. Belwal, R., Priyadarshi, P., \& Al Fazari, M. H. (2017). Graduate attributes and employability skills: Graduates' perspectives on employers' expectations in Oman. 31(6), 814-827. doi: doi:10.1108/IJEM-05-2016-0122

7. Cheong, K.-C., Hill, C., Fernandez-Chung, R., \& Leong, Y.-C. (2016). Employing the 'unemployable': employer perceptions of Malaysian graduates. 
Studies in Higher Education, 41(12), 2253-2270. doi:10.1080/03075079.2015.1034260

8. Chhinzer, N. (2018). An exploration of employer perceptions of graduate student employability. Education + Training, 60(1), 104-120. doi: 10.1108/ ET-06-2016-0111

9. Clark, M., Zukas, M., \& Lent, N. (2011). Becoming an IT Person: Field, Habitus and Capital in the Transition from University to Work (Vol. 4).

10. Gerhan, D. R., \& Mutula, S. M. (2007). Testing a recent model of ICT in development: Botswana and its university. Information Technology for Development, 13(2), 177-197. doi:10.1002/ itdj.20060

11. Hernández-March, J., Martín del Peso, M., \& Leguey, S. (2009). Graduates' Skills and Higher Education: The employers' perspective. Tertiary Education and Management, 15(1), 1-16. doi:10.1080/13583880802699978

12. Islam, T. (2015). Graduates' expectation gap: the role of employers and Higher Learning Institutes. Journal of Applied Research in Higher Education, 7(2), 372-384. doi:10.1108/JARHE-05-2014-0056

13. Jackson, D. (2012). Non-technical skill gaps in Australian business graduates. Education + Training, 54(2/3), 95-113. doi:10.1108/ 00400911211210224

14. Jackson, D. (2014). Undergraduate perceptions of the development of team-working skills. Education + Training, 56(1), 7-20. doi:10.1108/ET-012013-0002

15. Jusoh, M. (2011). Expectation gaps, job satisfaction, and organizational commitment of fresh graduates. Education + Training, 53(6), 515-530. doi:10.1108/00400911111159476

16. Lunn, K. (2003). Software Development Life Cycle. In K. Lunn (Ed.), Software Development with UML (pp. 53-68). London: Macmillan Education UK.

17. Mardis, M. A., Ma, J., Jones, F. R., Ambavarapu, C. R., Kelleher, H. M., Spears, L. I., \& McClure, C. R. (2018). Assessing alignment between information technology educational opportunities, professional requirements, and industry demands. Education and Information Technologies, 23(4), 1547-1584. doi:10.1007/s10639-017-9678-y

18. Martensen, A. (2009). Quality in higher education: linking graduates' competencies and employers' needs. International Journal of Quality and Service Sciences, 1(1), 67-77. doi:10.1108/ 17566690910945877

19. McMurray, S., Dutton, M., McQuaid, R., \& Richard, A. (2016). Employer demands from business graduates (Vol. 58).

20. Md Saad, M. S. (2014). Employers' perceptions of important employability skills required from Malaysian engineering and information and communication technology (ICT) graduates (Vol. 16)

21. Mukhtar, M., Yahya, Y., Abdullah, S., Hamdan, A., Jailani, N., \& Abdullah, Z. (2009). Employability and service science: Facing the challenges via curriculum design and restructuring.

22. Nair, C. S., Patil, A., \& Mertova, P. (2009). Reengineering graduate skills - a case study. European Journal of Engineering Education, 34(2), 131-139. doi:10.1080/03043790902829281

23. Nicolescu, L., Pǎun, C. J. T. E., \& Management. (2009). Relating Higher Education with the Labour Market: Graduates' expectations and employers' requirements. 15(1), 17-33. doi:10.1080/ 13583880802700024

24. Osmani, M., Weerakkody, V., Hindi, N. M., Al-Esmail, R., Eldabi, T., Kapoor, K., \& Irani, Z. (2015). Identifying the trends and impact of graduate attributes on employability: a literature review. Tertiary Education and Management, 21(4), 367-379. doi:10.1080/13583883.2015.1114139

25. Paguio, R. (2016). Teamwork from accounting graduates: what do employers really expect? Accounting Research Journal, 29(3), 348-366. doi:10.1108/ARJ-05-2014-0049

26. Shah, M., Grebennikov, L., \& Nair, S. (2015). A decade of study on employer feedback on the quality of university graduates (Vol. 23).

27. Stevens, M., \& Norman, R. (2016). Industry expectations of soft skills in IT graduates: A regional survey.

28. Tay, A. (2001). Management's perception of MBA graduates in Malaysia (Vol. 20).

29. Tickle, L., Kyng, T., \& Wood, L. N. (2014). The role of universities in preparing graduates to use software in the financial services workplace. International Journal of Mathematical Education in Science and Technology, 45(2), 200-213. doi:10.1080/0020739X. 2013.790518

30. Vilapakkam Nagarajan, S. (2014). The Relevance of University Studies to Professional Skills Requirements of IT Workplaces: Australian IT Graduates' Work Experiences (Vol. 2). 